
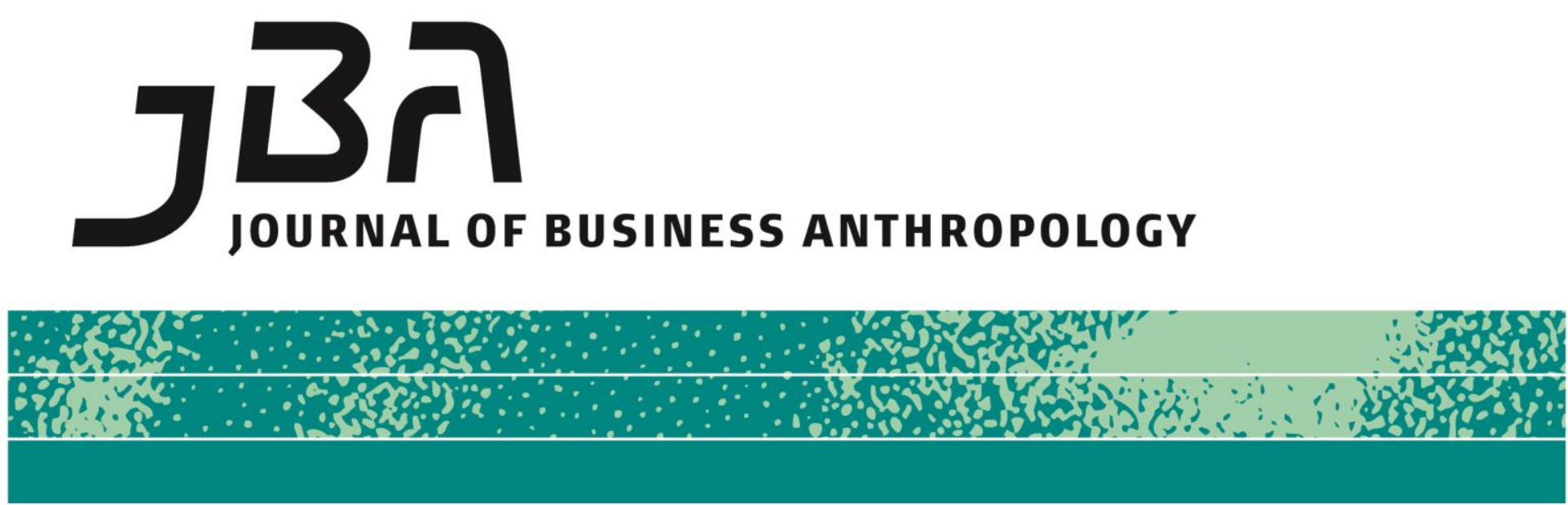

\title{
Creative Engagements Indeed! Open "Disciplines," The Allure of Others, and Intellectual Fertility
}

\author{
David A. Westbrook ${ }^{1}$
}

Just like asking after love suggests loneliness, asking after creative engagements invokes lack, perhaps even hunger. How many of us in the academy, to say nothing of the cubicle stalag, feel deeply disengaged? How many suspect that, although we work ostentatiously enough, our work could be done by others, or not at all, and so does not offer us the opportunities to be authors (parents, gods)? Are we neither creative nor engaged?

To shift imagery, we may sense that the intellectual jobs in which we find ourselves-that do so much to define us-were badly chosen. We were so ignorant back then, before graduate school, and so it is hardly unusual to feel that our careers have somehow failed to deliver what we came for, even if we are objectively fortunate, have good jobs, a degree of reputation, etc. Many academics feel that truth or at least intellectual satisfaction and in that sense engagement, to say nothing of creativity, the possibility of making something that will last a while, lies somewhere else. This feeling may be accepted, perhaps written off as common middle age disillusionment. The young at heart, however, may feel that if they

\footnotetext{
1 This essay stems from a presentation at the "Creative Engagements Workshop," University of Hong Kong, April 25-26, 2014. My hearty thanks to Brian Moeran and Dixon Wong for providing the occasion, and to George Marcus and Jack Schlegel for comments. The errors in judgment and otherwise are all mine.
}

Page 1 of 10

JBA 3(2): 170-179 Fall 2014

(C) The Author(s) 2014 ISSN 2245-4217

www.cbs.dk/jba 
have gone astray, then all the more reason to keep moving. Thus arises the interdisciplinary desire in the soul of the disappointed professional, the desire to cross fences.

In that psychological situation, the openness, even weakness, of one's own discipline may be an intellectual opportunity, a disguised strength. By "weak discipline" I mean, as a first cut, a discipline in which adepts have a high degree of willingness to accept and even use other disciplines. Conversely, the adepts of a strong or closed discipline see their questions as mostly or even exclusively answerable in terms of the discipline. Mathematics is probably the ultimate strong discipline; my contention is that law and anthropology are open disciplines. Not only that, anthropology and law are, or should be, open to one another.

Weak disciplines are less closely guarded; low fences are easy to climb. To be more specific: this essay tries to address, and perhaps modestly allay, common anxieties about living as professionals (intellectuals? knowledge workers? symbol manipulators? Academics?-it begins already) by exploring how the ill-defined characters of both "anthropology" and "law" may offer intellectual opportunity, and perhaps even the chance to be creative, to feel that work is worthwhile and in that sense to be engaged.

\section{Law as an Open Discipline}

Law schools in the United States are with varying fervor but always publically in favor of multidisciplinary approaches to law. There are numerous reasons for this. Law is a second degree - so all law students have studied something else in college. All of my students are in their mid 20 s or older. In the last generation or so, it has become increasingly common, on some faculties the norm, for law school professors to have advanced degrees in other disciplines. The cross training of US legal academics runs across the political spectrum. Law and economics is a staple at the most conservative institutions. Legal history, law and sociology, and so forth are all common.

SUNY Buffalo Law School is something of a leader in this regard. We credibly claim to be one of the preeminent "law and __." places in the country. So, by way of example, we have for over 35 years had an endowed "Baldy Center for Law and Social Policy" that combines the efforts of the law school with the social science faculties. Fourteen members of our faculty have PhDs in another subject, in addition to their law degrees (I am not one). Of perhaps particular interest here, we have five faculty members with PhDs in either anthropology or sociology. So, at least as a first cut, it would seem that law has fully taken the interdisciplinary turn, at least at some schools. In a law faculty discussion it would almost gauche to say that we should approach social questions from multiple, mutually enriching, perspectives. To do 
otherwise would be literally myopic, and we professors know that already.

This conclusion, however, is somewhat hasty. As suggested, questions of interdisciplinarity implicitly raise questions of what constitutes this or that discipline, and even what is meant by an "academic discipline." That is, understanding law in interdisciplinary terms implies that we have two disciplines here, much as "international law" tends to presume the nation that is precisely at issue. Apart from the administrative requirements of the bureaucratic university, it is hardly obvious that law (or even anthropology, as discussed below) should be understood, at a deep level, in terms of received notions of what constitutes an academic discipline.

There is certainly little consensus on what constitutes legal education, beyond the rather crude learning required to pass the bar exam. There is no substantive consensus on what should be on the bar exam, either, but in light of the institutional inertia at issue-the entire legal profession-the bar exam is unlikely to change much or quickly. Since passage of the exam is a sine qua non of the license, and the vast majority of law students seek to be licensed, schools perforce teach bar courses.

But that is rather prosaic: law must be more than teaching to a test rather circumstantially composed. But what? To many legal academic, the mere suggestion of a single idea, question, or approach (along the lines of "economics concerns the problem of scarcity") that (i) unites legal research, and that (ii) is relatively objective, to be discovered and studied with cold dispassion, i.e., is THE object of research, seems so implausible as to suggest bad faith, no doubt some hegemonic agenda.

I do not mean to overstate the matter. Lawyers in the United States of course recognize one another, have distinctive ways of knowing, talking, and operating. Reaching back, the study of law is central to the emergence of the University in the West, i.e., it could be argued that not only is law a discipline, it is the first of disciplines (though the physicians and the theologians may demur). The problem is that while it is not too difficult to gain "we know it when we see it" understandings of law in the university (and indeed in society writ large), such loose understandings are intellectually, and ultimately psychologically, impoverished, and so unsatisfying in a very specific sense. The academic locates herself in a field, and if the field is ill-defined, then the academic is not located. Worse, the academic cannot claim exclusive authority (a very legal concept) vis-a-vis other academics over the domain. The bounds of the domain are fluid and so easy to contest. In a world in which a career, and so a sense of public self, is founded on (intellectual) authority, this puts the law professor in a precarious position, only somewhat mitigated by the reflected glory of law in an intensely legalistic society. From this perspective, we may think of law as a "weak" discipline, incessantly 
invaded yet so central as to be sort of immortal, like Belgium in European history.

At the same time, the very prevalence of "law and __" suggests that legal scholars feel the need to import [something] to shore up the borders. In the relatively short history of American legal education in the context of the University (as opposed to legal education via apprenticeship), there have been numerous efforts to "ground" law, or what often comes to the same thing, to reform it, by importing wisdom from other fields. Christopher Columbus Langdell, the first dean of Harvard Law School, argued that the jumble of the common law could be rationalized on the analogy of chemistry, with appellate courts as "laboratories" and decisions as "data." A subsequent dean of Harvard, Roscoe Pound, shifted the regulative ideal to his field, biology, which allowed for ideas of evolution, and nods towards contemporary German historical thought. Law was, in several senses of the word, a progressive undertaking.

A generation later, in the 1930s, under the banner of "American Legal Realism," law professors loudly disavowed their allegiance to "doctrine," which was seen as endlessly malleable and therefore not objective and consequently unfit to comprise the discipline of law. Instead, American legal realists said -- quoting Holmes -- that they were going to treat law as it was in fact, and many pledged troth with the social sciences, and not incidentally, the New Deal. But, as John Henry Schlegel describes with some wickedness, the entire project didn't really "take." Doctrine never really went away, not least for practical reasons. Doctrine is and was the easiest way to teach rules, and for that matter to teach students how to make arguments that sound plausible to judges and defensible to clients, and the easiest thing to test on the bar exam. Nor did law professors, by and large, get very far as social scientists. Working out the New Deal, or later, the Civil Rights movement, or environmental law, or even making a lot of money for one's clients on Wall Street, evidently seemed a much more sensible use of intellectual horsepower than endless noodling over what "really" happens in society.

Beginning around the time of Vietnam, law and economics scholars extended the sociological project of American legal realism by arguing that law should aim to achieve economically efficient outcomes conceived under a hypothesized optimal set of rules. That is, the vocabulary and grammar of neoclassical economics were used in an explicitly normative (generally speaking, conservative) program of law reform. As a movement, law and economics was vastly successful, but given its fairly overt political engagements (some of which were astonishingly creative), difficult to see as particularly wissenschaftlich.

Unsurprisingly, shortly thereafter, a number of scholars whom we may generally speaking call "critical" (there was a "Critical Legal Studies Movement") attempted to redefine law by extending the skepticism of 
American Legal Realism toward doctrine and judicial decisions toward law itself. Drawing on various social sciences, literary theory, and an increasingly implausible Marxian impulse, as well as the morally reassuring notion that law was a form of advocacy to be used for the disenfranchised, critical legal thought argued that law tends to entrench (presumptively unjust) hierarchies. Aided by social sciences and the humanities, the function of legal scholarship was to reveal such injustice, thereby unsettling the authority of (unjust) law, and paving the way for new, more just, law. Again, interesting, but hard to understand as an objective program of research. And if no objective program of research can be stated, it seems unlikely that law should be understood as an autonomous discipline.

I should mention that the multidisciplinary ideal has not gone unchallenged. There have long been efforts to make law an autonomous discipline (to make the fences defensible) by restricting the domain of law to obviously "legal" output-statutes, judicial decisions, and the like. We might, broadly speaking, call this the positivist impulse: law is what the sovereign posits through legal institutions. This impulse is rather more dominant in legal studies outside the United States.

The problems with treating law as an autonomous discipline are manifold, and acute in a society like the United States. In the United States, law is everywhere. Even those areas of life that we regard as "private" are often intensely legally articulated. Officers of a corporation, for example, are empowered to act, or not, by law, but also by the business of the firm itself, which is also a social and economic and historical matter. Americans think about lots of things, ranging from sports to sex, in legal(istic) terms, a characteristic noted by Tocqueville. And building on Tocqueville with a dash of Rousseau, we might think that any large (and diverse and therefore somewhat alienated) society will perforce turn to law to regulate relations that cannot be felt. Consider, in this regard, European law.

At a deeper level, even "prelegal" relations might be felt to be the real law. As Holmes has it, law comprises the "felt necessities" of an era. And so we Americans sometimes decide that duly passed "laws" are unconstitutional, i.e., not really law, in the name of some higher law embodied in the Constitution, truths that we (now) hold to be "self evident," as Jefferson has it in the Declaration. See, generally, civil rights, latterly gay marriage.

\section{Cultural anthropology as an Open Discipline}

If so inclined, for an undergraduate textbook perhaps, one might define anthropology etymologically, as the study of mankind. If the purpose of having a discipline is to organize and focus thought, however, then such a broad understanding does not help much. 
Not unlike law, however, in practice and for many years it was not difficult to tell what counted as anthropology. Traditionally, "mankind" was reduced to "culture," and by "culture" one meant "other cultures," i.e. the native, the exotic, etc., which could be studied as objects, i.e., more or less scientifically, by the ethnographer. Cultural anthropology may have been somewhat ill-defined, but for years it plausibly held itself forth as a discipline, in which objective research was conducted.

All of these phrases-culture, native, etc--have become intensely problematic since the turn to interpretation that anthropology took during the ' 80 s, which we might call, by way of short-hand, the "Writing Culture" critiques, after the book of essays edited by James Clifford and George Marcus. As suggested above, there was a parallel, and less successful, moment in law, known as Critical Legal Studies.

At the same time, the material conditions that cultural anthropology was devised to interrogate-the native, the exotic, the entire Malinowskian gig-sank into the swamp of globalization. The native was affected by the metropole; the metropole itself seemed in need of ethnographic inquiry. Confusion proliferated. In certain intellectual quarters, the working presumptions that had sustained cultural anthropology in fact (university sophisticate reports on native practices and their meaning in a scholarly idiom) came to seem implausible, even politically suspect. "What does it mean to do anthropology today?" became a good question.

In more official but perhaps less thoughtful quarters, of course, it was and is maintained that all is well with anthropology. University bureaucracy can have it no other way, at least not without massive disruption, which is to be avoided. So the university will without a doubt continue to pursue "excellence" in cultural anthropology, as in all else.

More seriously, however, there did and does seem to be much that was truly important in the traditional anthropological project, colonial associations and all, much that should be saved even though the world and our sensibilities have shifted. Rephrased, refunctioning ethnography, profoundly revising it yet preserving, somehow, its heart, has come to seem a worthy project to any number of contemporary anthropologists. Which brings us fairly close to the raison d'etre of this journal, which implicitly (and sometimes explicitly) asks how could cultural anthropology, and more specifically ethnography, reinvent itself in order to engage "present situations," including contemporary business life?

Asked explicitly, the problem is easily abstracted, yielding theoretical questions: can we articulate a philosophy of new-fangled anthropology, and conversely, describe a possible practice of such anthropology in general terms? One set of answers, based on conversations with George Marcus and Doug Holmes, is articulated in my book, Navigators of the Contemporary: Why Ethnography Matters. For whatever it may be worth, in that book and since, I have explored what 
such answers might mean for my own discipline, law, and for intellectual and political life more generally. But I digress.

Like law, cultural anthropology lost much of its pretension to be an objective and sharply delineated discipline, and came to understand itself as comprising inherently interpretive, and hence somewhat vague and sentimental, inquiries, in the hope that non-anthropologists have answers. In short, open.

\section{How Are Contemporary Law and Anthropology Alike?}

Quite apart from their openness, law and anthropology are alike in another way: the temporality of their foci. Both law and anthropology of the contemporary often focus on the emergent, the assemblage, the present and often quite fluid situations that people in contemporary societies construct together. Businesses are an important example, as the existence of this journal attests.

Such "present situations" are often unbearably complex. For example, the instructions to banks for applying the "Volcker Rule" regarding permissible investment of moneys under their control run to almost 1000 pages, which cannot be completely trusted because open to revision. To make matters worse, the Volcker Rule is a small part of the Dodd-Frank Act, itself almost 1000 pages. In response, the financial professions give conferences, experts are established, authoritative readings sought and paid for ... In short, the complexity of large scale, profoundly imbricated, seriously influential yet highly regulated industries gives rise to the Washington legal practice of discerning, articulating and contesting what the relevant players now think the law is.

So the "subjects" of the disciplines-both "law" and "culture"-turn out to be inherently ill-defined, because the emergent has, by definition, not yet emerged. The not yet arrived is not quite here; the status quo (for this moment, which will not last long) is not easy to discern. One may of course overdo the point; history is unavoidable. Surely people have commitments and understandings on the basis of which they conduct their affairs, but such foundations are incomplete, vague, contested-and evolving. What, after all, did (or does) the US Constitution, to say nothing of "the Treaties" that constitute the EU, mean? What does it mean to say that a society is, say, "liberal," or, heaven forefend, "modern"?

Understanding the near future as a foggy extension of a hazy past to be the object, or perhaps terrain, of inquiry and contestation means that legal and anthropological scholarship comprises more or less toughminded description, with more than a bit of speculation. It is a bit vain to think of this as "research" in the classical sense to which Wissenschaft aspired-simply too much critical judgment is involved, to say nothing of hope and fears, and normative tendencies under the best of 
circumstances-how do we feel about the world we sense is emerging?

This intense interest in a future that is not yet completely decided, and about which we may believe many things, goes far to explain why law did not become-despite many efforts-a social science. But while the desire for reform is front and center in US legal scholarship, the engagement (things could be better, if we only...) runs, by definition, through engaged scholarship. At which point the claim that the scholar simply "knows" becomes risible. The pertinent question is why should we believe this scholar's claim that what she believes she knows is important? Why should we feel similarly about the matter?

This lack of intellectual definition provides opportunities to work as an intellectual in a wide variety of ways and settings. As the objects of thought emerge in shifting fashion, the mix of ways we think about such objects is likely to shift, as well. Some approaches will seem more or less trenchant at different times; at other times, other approaches may make more sense. For that reason, I strongly support the "welcome" that Moeran and Garsten provided at the launch of this journal, in which "business anthropology" was seen as a terrain on which people from various backgrounds and with diverse research credentials could meet and talk in thoughtful but straightforward English about the meaning of trade. What Moeran and Garsten did not do, and have struggled not to do since, is declare business anthropology to be its own subdiscipline, which would require lots of effort to maintain the inescapably arbitrary definition, police the jurisdiction. It is not only easier but deeper to provide a space for thinking together as best we can, as the occasion arises.

\section{Conclusion: Refunctioned ethnography can help law; law can help cultural anthropology}

In order to operate in complex present situations, people must tell themselves stories about the lay of the land-they must be "ethnographers unto themselves." This is particularly true in present situations, i.e., just presenting themselves, and therefore not yet wellmapped by traditional narratives.

What George Marcus and Doug Holmes call "paraethnography" seeks to utilize these "lay" articulations of social structure to construct an academic account of the situation (or assemblage, etc.). For example, the understanding within a company of what it is/means/requires to develop and market a new perfume might be articulated by those involved, and then reworked by the ethnographer into a text to be read by academics, people who have neither developed nor marketed anything. Paraethnography thus provides a way of making the contemporary cognizable within the academy, that is, supporting the kinds of production required by academics. It is a way to continue to do ethnography at the 
present time.

All this is well and good for anthropologists, but even more interestingly for my purposes, paraethnography could matter for the practice of law and politics. Specifically, paraethnography could give regulators (and the rest of us) purchase on the complex environments that they seek to secure. For example, once we realize that Basel III is so complex as to be fundamentally unclear as text, then the question becomes what do those in power understand in fact-some understanding is unavoidable, some law is enforced? What is the lore? Ethnography can articulate that. In principle (but not in current practice) there is no reason that such understandings could not become the basis of regulation, i.e., liability, and institutional control. (Especially the prudential regulation of large financial institutions.) And this is the kind of point that makes ethnography far more important, both politically and intellectually, than anthropologists seem to realize-ethnography seems to be one of the few ways to gain a substantive, internal, purchase on the bureaucracies that conduct so much modern politics, perhaps even a way of doing sensible if not enlightened politics in a post-enlightened age, of making some sense, for example, of our "defense" policy.

At the same time, I think law has something valuable for cultural (and social) anthropology. Cultural anthropologists might begin (are beginning?) to understand the law not as a form that fails to describe the social, or worse, that fails to achieve "social justice" (bracketing "asocial justice") or, in zombie Marxian fashion, as mere superstructure serving the interests of the powerful, defined somehow otherwise. Instead, it would be useful for anthropologists to understand law as doctrine in the theological sense, a formalization of belief, and hence a fairly straight path into the heart of the social. Law is serious business. Law is established through expensive political contests; law imposes great costs; law is generally backed by the explicit power of the state. Not everything serious, not everything right, is expressed by a law. But if we ignore laws that have fallen into desuetude and remain "dead letter" texts out of institutional laziness, those things that are commanded, or fostered, by laws do indicate commitments of the powerful. Consider, in this regard, laws mandating spending, or establishing an agency and giving it jurisdiction over some aspect of social life. And so even a superficial reading of the law can bring us pretty close to understanding the vitals of what used to be called, without irony, culture.

It is important for present purposes to emphasize that I am talking about fairly straightforward readings ("superficial" is perhaps too strong) of the law. I am not talking about "what the law really means," despite what it says. What statutes, decisions, regulations and officials (including judges, government officials, and even corporate officers) say, in public and baldly, is important. This also has a practical benefit for cultural anthropologists: such statements are public. One does not need to travel, 
much less acquire special access, to begin thinking about what an investment bank or a general staff, for examples, claim to believe, how such groups present, and in that sense understand, themselves. Thus, for those who care to understand power, a bit of attention to what law and those authorized by law say could go some distance toward ameliorating the problems of access to powerful figures in business (and other) fieldwork sites of interest to contemporary anthropology.

Let me conclude. In confronting the complexities of contemporary life, it is to be hoped that legal thought and even regulatory practice will take a paraethnographic turn. Conversely, perhaps cultural anthropologists will more readily comprehend law as the formalization of belief, and hence the ways that laws, or their substrate, everywhere inform social practices, including the practices of academics. There is a great deal of terrain for creative engagement.

David Westbrook is Louis A. Del Cotto Professor of Law, Director for Global Strategic Initiatives, State University of New York at Buffalo Law School, and author of Navigators of the Contemporary: Why Ethnography Matters (University of Chicago 2008). He may be reached at dwestbro@buffalo.edu 